\title{
Educação histórica e a contribuição para a formação de professores: experiências de pesquisa
}

\author{
Historical education and its contribution to teacher training: research \\ experiences
}

\section{Educación histórica y la contribución a la formación docente: experiencias de investigación}

\section{Geyso Dongley Germinari'}

Universidade Estadual do Centro-Oeste, Professor adjunto. https://orcid.org/0000-0002-4797-7113

Ana Claudia Urban ${ }^{2}$

Universidade Federal do Paraná, Departamento de Teoria e Prática de Ensino, Setor de Educação, Professora.

https://orcid.org/0000-0001-9957-8838

Resumo: 0 artigo apresenta contribuições de dissertações que discutem a aprendizagem histórica na perspectiva da Educação Histórica produzidas no Programa de Pós-graduação Stricto Sensu em Educação da Universidade Federal do Paraná (UFPR) e nos Programas de Pós-graduação Stricto Sensu em Educação e História da Universidade Estadual do Centro-Oeste (Unicentro). As pesquisas em Educação Histórica tomam como objeto de investigação os processos de aprendizagem histórica no âmbito escolar, aproximam-se desse fenômeno por meio do levantamento das ideias históricas (substantivas e de segunda ordem) de estudantes e professores e as analisam com os recursos da teoria e filosofia da História. As pesquisas inventariadas revelam movimentos das investigações fundamentadas nos princípios da Educação Histórica e indicam relação intrínseca com os processos de escolarização.

Palavras-chave: Educação Histórica. Formação de professores. Pesquisa.

Abstract: This article presents an analysis of dissertations that discuss historical learning from the perspective of Historical Education, produced under the Stricto Sensu Graduate Program in Education at Federal University of Paraná (UFPR) and in the Stricto Sensu Graduate Program in Education and

Doutor e Mestre em Educação pela Universidade Federal do Paraná.

Doutora em Educação pela Universidade Federal do Paraná; Mestre em Educação pela Universidade Estadual de Ponta Grossa. 
History of the Midwest State University (Unicentro). Research in Historical Education takes as its object of investigation the processes of historical learning in the school environment and approaching this phenomenon by surveying the historical ideas (substantive and second order) of students and teachers; analyzing them with the resources of theory and philosophy of History. The inventoried researches reveal movements of the investigations based on the principles of the Historical Education and indicate intrinsic relation with the processes of schooling.

Keywords: Historical Education. Teacher training. Research.

Resumen: El artículo presenta un balance de disertaciones que discuten el aprendizaje histórico desde la perspectiva de la Educación Histórica producida por el Programa de Posgrado en Educación Stricto Sensu de la Universidad Federal de Paraná (UFPR) y en los programas de Posgrado en Educación e Historia Stricto Sensu de la Universidad Estatal del Medio Oeste (Unicentro). Las Investigaciones en Educación Histórica toman como objeto de investigación los procesos de aprendizaje histórico en el entorno escolar, se acercan a este fenómeno por medio del listado de las ideas históricas (sustantivas y de segundo orden) de estudiantes y profesores y las analizan con los recursos de la teoría y filosofia de la Historia. Las investigaciones inventariadas revelan movimientos de las investigaciones basadas en los principios de la Educación Histórica e indican una relación intrínseca con los procesos de escolarización.

Palabras clave: Educación histórica. Formación de profesores. Investigación.

Recebido em 31 de agosto de 2019

Aceito em 18 de maio 2020

Publicado em 16 de junho de 2020

\section{INTRODUÇÃO}

0 ensino de História como campo de pesquisa agrega investigações sob diversos ângulos teóricos e metodológicos, integra tanto análises diacrônicas (história do ensino de história), quanto reflexões sobre problemas atuais de ensino e aprendizagem de História. É dentro da segunda perspectiva que se encontram as investigações em Educação Histórica. Assim, compreende-se que a Educação Histórica se constitui como uma linha de pesquisa dentro do universo mais amplo das investigações em ensino de História.

A Educação Histórica centra suas análises nos processos de aprendizagem histórica no ambiente escolar. Diferencia-se de outras linhas de pesquisa que abordam a aprendizagem de história na escola pela sua fundamentação teórica baseada na ciência da 
história, distanciando-se, por exemplo, dos referenciais da pedagogia e da psicologia, áreas tradicionais da pesquisa em educação escolar.

0 campo de pesquisa em Educação Histórica vem se definindo com suas especificidades próprias, em diferentes países e também no Brasil. Pesquisadores enfatizam a importância dessas pesquisas para uma teoria da aprendizagem histórica, na medida em que busca o conhecimento das ideias históricas de jovens, crianças e professores, definindo a sua especificidade em relação a outras pesquisas que tomam como objeto o ensino e aprendizagem da História. As especificidades do campo têm sido delineadas por autores como Rüsen (2010), Barca (2005) e Schmidt (2009b), os quais recorrem, principalmente, aos fundamentos da epistemologia da História, especialmente a teoria da aprendizagem e a formação da consciência histórica.

Nessa perspectiva, dois conceitos assumem centralidade. Por um lado, o processo de aprendizagem histórica é entendido a partir do conceito de pensamento histórico, delineado pelos estudos de tradição anglo-saxônica, e, por outro lado, o mesmo processo é compreendido como resultado da formação da consciência histórica, uma discussão teórica empreendida por filósofos da história alemães. As duas tradições têm alimentado as pesquisas em Educação Histórica no Brasil.

As investigações em Educação Histórica vêm sendo desenvolvidas por diversos grupos de pesquisadores e pesquisadoras no Brasil. Neste artigo serão mencionadas algumas pesquisas de mestrado desenvolvidas nos Programas de Pós-graduação Stricto Sensu em Educação e História, respectivamente nas linhas de pesquisa Educação, Cultura e Diversidade e Espaços de Práticas e Relações de Poder da Universidade Estadual do CentroOeste (Unicentro) e da Pós-Graduação Stricto Sensu em Educação, na Linha de Cultura, Escola e Processos Formativos em Educação da Universidade Federal do Paraná (UFPR), defendidas no período entre 2017-2019. As pesquisas foram escolhidas por destacarem alguns dos pressupostos da Educação Histórica e por terem sido orientadas pelos autores do texto, no momento da pesquisa, orientadores de mestrado.

Organizado em dois momentos, o artigo primeiramente apresenta os fundamentos teóricos e metodológicos que têm orientado as pesquisas em Educação Histórica desenvolvidas na UFPR e na Unicentro, para, em seguida, expor alguns resultados das produções elaboradas nas instituições mencionadas. 


\section{PRINCÍPIOS TEÓRICOS E METODOLÓGIICOS DA EDUCAÇÃO HISTÓRICA}

Na Inglaterra, país pioneiro nas pesquisas em Educação Histórica, o debate nas últimas décadas tem acontecido em torno de duas preocupações. Por um lado, professores e pesquisadores concentram a preocupação no desenvolvimento do raciocínio histórico (referenciado na ciência da história) dos estudantes de todos os níveis de escolaridade. Por outro lado, alguns professores, muitos historiadores e o público leigo estiveram mais preocupados com o que os alunos deveriam saber sobre o passado no final dos seus estudos de história na escola.

Considerando a necessidade de maior aproximação do ensino de História com a compreensão dos estudantes acerca da relação da História escolar com os pressupostos da ciência da história, as primeiras pesquisas na perspectiva da Educação Histórica começam a ser desenvolvidas na segunda metade do século XX. Os primeiros passos da Educação Histórica foram dados na década de 1960, na Inglaterra, no contexto de uma reestruturação curricular, na qual se diagnosticou o afastamento dos alunos da disciplina de História, uma vez que a disciplina era optativa. Em suma, os estudantes não se interessavam pelas histórias contadas na escola, eles gostavam "[...] mais das histórias da TV, dos livros, etc. Em vez de aprenderem conhecimentos substantivos sobre o passado, os alunos aprendiam 'estórias'." (LEE, 2001, p. 13). Com o objetivo de superar a situação de descrédito da disciplina de História foi organizado o Projecto 13-16, voltado para alunos entre 13 e 16 anos, coordenado na sua última fase pelo pesquisador Denis Shemilt, o qual visava investigar modos de ensinar História em termos da ciência da história. A partir do Projeto, houve um crescimento da disciplina em toda a Inglaterra. Peter Lee (2001, p. 14) lembra o momento:

\footnotetext{
Mais de um terço das escolas passaram a seguir este projeto, desenhado para crianças dos 13 aos 16 anos. Eu próprio, que inicialmente fui crítico deste projeto, vi que de fato funcionava. Os professores trabalhavam em grupo e gostavam. Houve uma mudança nesta disciplina, surgiram novas ideias sobre o ensino da História.
}

Esse contexto foi a "mola propulsora" para o desenvolvimento das primeiras pesquisas em Educação Histórica na Inglaterra. Atualmente, as investigações em Educação Histórica também vêm sendo desenvolvidas, além da Inglaterra, com certa intensidade em países como Estados Unidos, Canadá, Espanha, Portugal e Brasil. No esforço de definição do campo da Educação Histórica, Barca (2005, p. 15) sintetiza seus principais contornos: 
Nestes estudos, os investigadores têm centrado a sua atenção nos princípios, tipologias e estratégias de aprendizagem histórica, sob o pressuposto de que a intervenção na qualidade das aprendizagens exige um conhecimento sistemático das ideias históricas dos alunos, por parte de quem ensina le exige também um conhecimento das ideias históricas destes últimos).

As análises sustentadas nos pressupostos teórico-metodológicos do conhecimento histórico assumem, na atualidade, um conjunto de enfoques que podem ser resumidos em três núcleos: a) análises das ideias de segunda ordem; b) análises relativas às ideias substantivas e c) reflexões acerca do uso do saber histórico.

As pesquisas das ideias de segunda ordem buscam compreender o pensamento histórico de acordo com critérios de qualidade, ancorados nos debates contemporâneos referentes à filosofia e teoria da História. Nesse enfoque, não interessam as questões relativas à quantidade ou simples correção de informações factuais do passado, mas as questões relacionadas ao raciocínio e à lógica histórica, como o desenvolvimento dos conceitos de evidência histórica, causalidade, narrativa histórica, empatia histórica, entre outros conceitos que compõem a natureza epistemológica da história. Estudos seminais sobre desenvolvimento de conceitos de segunda ordem no processo de aprendizagem histórica de crianças e jovens foram realizados no Projeto Chata (Concepts of History and Teaching Approaches), coordenado por Rosalyn Ashby, Peter Lee e Alaric Dickinson, que investigou ideias históricas de segunda ordem de crianças e adolescentes ingleses de seis aos 14 anos de idade. A pesquisa utilizou uma amostra de 320 alunos (três escolas primárias e seis escolas secundárias). Os alunos foram inquiridos sobre: compreensão de causas em História, empatia, objetividade da pesquisa histórica, evidência e narrativa histórica (LEE, 2001).

A análise de ideias substantivas concentra-se em reflexões a respeito dos conceitos históricos, como, por exemplo: revolução, democracia, renascimento, comumente denominados como os conteúdos de ensino. Essas análises também utilizam critérios de qualidade, destacando valores e motivações associados aos conceitos substantivos da História. Um exemplo desse tipo de pesquisa é a dissertação de Castex (2008), que investigou como um grupo de jovens estudantes dos anos finais do ensino fundamental da Rede de Ensino de Curitiba compreendem o conceito de ditadura militar brasileira e as relações com o processo de escolarização. A questão central foi analisar se a educação escolar dos jovens era tomada como referência para construção das ideias sobre ditadura militar brasileira. Os resultados indicam que as ideias dos estudos, nesse caso, são construídas pelo contato com a perspectiva historiográfica presente na escola por meio do livro didático de história e prática de ensino dos professores, mas, também, pela memória coletiva. Por fim, as investigações referentes ao uso do saber histórico analisam questões relativas ao significado e uso da História na vida cotidiana. 
Diferente da pesquisa acerca do desenvolvimento cognitivo da aprendizagem, referenciada na Psicologia da Educação, as análises da cognição no viés da Educação Histórica tomam como referência a própria epistemologia da História. Parte-se da premissa de que existe uma cognição própria da História, fundamentada na epistemologia da ciência da história ou, em outras palavras, no pensamento histórico científico. Schmidt (2009b) pondera a respeito da importância das teorias psicológicas e suas categorias nos processos de aprendizagem de crianças e jovens, principalmente para as mediações didáticas em sala de aula. No entanto, destaca que tais categorias não se referem à cognição história, a qual pode ser denominada cognição histórica situada na ciência da História. Assim, a análise da cognição histórica requer um enquadramento teórico específico circunscrito à natureza do conhecimento histórico, ancorado na epistemologia da História.

Como destaca a pesquisadora Schmidt (2009a), na perspectiva da cognição histórica situa-se a forma pela qual o conhecimento histórico na escola deve ser aprendido pelo aluno e deve ter como base os pressupostos da ciência da história, ou seja, o desenvolvimento cognitivo em situações de ensino e aprendizagem ampara-se na epistemologia da ciência da História. Dessa forma, a aprendizagem histórica significa desenvolver progressivamente ideias balizadas pelo conhecimento histórico científico, como a pluralidade de interpretações e narrativas acerca do passado, o conceito de evidência histórica a partir de inferências em fontes e a noção de causalidade histórica.

Nos últimos anos, a Educação Histórica tem incorporado em suas pesquisas o conceito de consciência histórica. Na perspectiva do historiador alemão Jörn Rüsen acerca dessa incorporação, Lee (2002, p. 1) reconhece que a ideia de consciência histórica possibilita a reconceitualização do campo de investigação, pois

\footnotetext{
"A consciência histórica" sugere uma perspectiva teórica integrativa capaz de subordinar duas tendências relacionadas, e talvez uma tradição bastante diferente. Ela traz a perspectiva de convergência entre o crescente interesse mostrado por muitos historiadores naquilo que pode ser chamado "memória" e o foco do ensino de História nas imagens que os estudantes têm do passado.
}

Essas investigações tiveram origem na Alemanha. A utilização do conceito de consciência histórica no ensino de História emergiu das discussões entre especialistas em didática das antigas RDA 3 e RFA na década de 1980. Nas palavras de Jung e Staher (1998, p. 138): "os anos 80 se caracterizaram por uma aproximação entre didatas da história mais progressistas e

República Democrática Alemã.

República Federal da Alemanha. 
os mais conservadores. Essa aproximação cristalizou uma aceitação generalizada da categoria de 'consciência histórica' como categoria central da didática da história".

Depois foram desenvolvidas investigações em vários países, tendo como referência principal o conceito de consciência histórica delineado pelo historiador Rüsen. A maior pesquisa nessa área foi desenvolvida por Angevik e Borries em 1997. Trata-se de uma enquete aplicada em 25 países europeus, mais Palestina, Israel e Turquia, com um conjunto de 32 mil jovens de 15 anos, para conhecer, sob orientação de um questionário, o conteúdo da sua consciência histórica. Essa pesquisa definiu a consciência histórica como uma operação mental complexa que estabelece conexão entre a interpretação do passado, a compreensão do presente e a expectativa do futuro.

Os estudos sobre a cognição histórica de alunos e professores, tendo como referência o conceito de consciência histórica, estabelece novo significado para o conceito de aprendizagem histórica escolar quando rompe com a dicotomia entre a ciência da história centrada na metodologia da pesquisa e o ensino/aprendizagem de História na escola, orientado pelas metodologias de ensino fundamentadas na didática geral e na pedagogia.

Dessa forma, a Educação Histórica colabora para a recuperação da dimensão didática da ciência histórica, perdida a partir da crescente institucionalização e profissionalização da História, desde o final do século XIX. Processo que, por um lado, levou à valorização da metodologia da pesquisa em detrimento das dimensões didáticas do conhecimento histórico e, por outro lado, transformou a Didática da História em um saber "[...] que faz a mediação entre a história como disciplina acadêmica e o aprendizado histórico e a educação escolar." (RÜSEN, 2006, p. 8).

Nesse movimento, houve um esforço dos historiadores na demonstração da cientificidade do conhecimento histórico pela via do método. Assim, nesse momento, a História transforma-se em ciência com objeto e método próprios. Uma das consequências desse contexto foi o afastamento gradativo da reflexão sobre os problemas didáticos intrínsecos ao conhecimento histórico, como a relação com a vida prática e as dimensões da aprendizagem histórica presentes no processo de produção científica do saber histórico.

Desse modo, com a crescente especialização da História como ciência, a Didática da História passa a ser compreendida como um campo de conhecimento externo à ciência da História, cuja função é mediar a relação entre o conhecimento histórico produzido pelos historiadores e o processo de ensino-aprendizagem que ocorre nas escolas. Nessa perspectiva, a função da Didática da História seria traduzir e transmitir aos alunos e alunas os produtos do conhecimento histórico científico (RÜSEN, 2007).

0 filósofo da história, Rüsen, em suas discussões sobre enraizamento do pensamento histórico comum e científico na vida prática concreta, recupera a reflexão 
didática do conhecimento histórico, enfraquecida a partir do século XIX, para agora colocá-la no centro do debate sobre a racionalidade da ciência da história. Ele argumenta que

\begin{abstract}
a didática da história se situa nessa relação direta com a ciência da história, na medida em que se concebe como ciência do aprendizado histórico e não como ciência da transmissão do conhecimento histórico produzido pela ciência da história. No que segue, entende-se "aprendizado histórico" como o processo de formação da identidade e orientação histórica mediante as operações da consciência histórica. (RÜSEN, 2012, p. 16).
\end{abstract}

Condição antropológica, a consciência histórica refere-se às determinadas operações mentais, concernentes às carências temporais que afligem a vida de todos os homens e mulheres. Nas palavras de Rüsen (2001), a consciência histórica é a articulação de três estruturas mentais: a experiência, a interpretação e a orientação temporal, operações específicas que fornecem sentido à vida humana no tempo. As experiências do tempo vividas como mudanças do mundo e de si mesmo desestabilizam a vida e causam sofrimento, por isso, carecem de ser interpretadas para orientar o agir humano na vida concreta de modo intencional. Assim, consciência histórica pode ser descrita como

[...] o trabalho intelectual realizado pelo homem para tornar suas intenções de agir conformes com a experiência do tempo. Esse trabalho é efetuado na forma de interpretações das experiências do tempo. Essas são interpretadas em função do que se tenciona para além das condições e circunstâncias dadas da vida. (RÜSEN, 2001, p. 59).

0 resultado desse trabalho mental é a constituição de sentidos históricos (articulação entre passado, presente e futuro) que orientam o agir na vida prática.

Por esse caráter orientador do agir humano, Rüsen (2007, 2010, 2012) compreende o exercício da consciência histórica como um processo de aprendizagem histórica. Em outras palavras, é o ato de interpretar a experiência do passado para compreender o presente e perspectivar o futuro, de modo a orientar as ações na vida prática, podendo ser caracterizado como a geração de um aprendizado histórico.

Ainda nesse sentido, a relação com a temporalidade realizada na consciência humana é compreendida como um processo de aprendizagem, porque orienta o indivíduo nas questões temporais que afetam a sua vida. Essa função essencial ocorre em dois sentidos: orientação temporal da vida prática externa e interna. A orientação temporal externa relaciona-se à práxis, e a interna, à formação da identidade histórica. Desse modo, aprender 
história significa desenvolver a capacidade de orientação temporal, mediando as operações essenciais da consciência histórica.

Como disciplina específica da teoria da história, a Didática da História abre-se para o vasto campo das atividades e funções da consciência histórica e da aprendizagem histórica, e pergunta com interesse sobre as contribuições da ciência histórica para o desenvolvimento das competências da consciência histórica pertinentes à aprendizagem, que "[...] são necessárias para resolver problemas práticos de orientação com o auxílio do saber histórico." (RÜSEN, 2007, p. 94).

A Didática da História, ou ciência do saber histórico, pode demonstrar para o profissional, preocupado exclusivamente com os conteúdos e com a quantidade de informações, que existem conexões possíveis entre a História, a vida prática e a aprendizagem, e são elas as responsáveis pela forma como se aprende a História e, na condição de professores, pela forma como se ensina a História.

Os contributos de Rüsen $(2001,2007)$ para as reflexões de caráter epistemológico sobre a forma de aprender e ensinar a História têm permitido localizar a Didática da História dentro de um corpo teórico que tem, entre os objetivos, o desenvolvimento de uma consciência histórica que, por sua vez, é identificada como preocupação central das pesquisas situadas no campo da Educação Histórica. Nessa perspectiva, Educação Histórica dialoga com a Didática da História, considerada como uma disciplina especializada, cuja problemática da aprendizagem histórica e sua relação com a formação da consciência histórica são centrais para os estudos da Educação Histórica.

Entende-se, assim, que o substrato da Didática da História, defendido por Rüsen, está baseado na natureza da ciência da História, sendo que a consciência histórica está, por assim dizer, presente nesse substrato, pois, para o autor, a consciência histórica está presente no fundamento da ciência da História.

A perspectiva para o entendimento da obra de Rüsen sustenta-se na compreensão de como se constitui a cognição histórica, e essa forma de aprender é pautada numa teoria, a teoria da História que, por sua vez, contém uma Didática.

Na obra História Viva - Teoria da História Ill: formas e funções do conhecimento histórico, Rüsen (2007) dedica um capítulo sobre a função didática da História. Pondera o autor que a "Didática" é um conceito ambíguo no campo do pensamento histórico. Afirma que:

0 termo "didática" indica que a função prática do conhecimento histórico produz efeitos nos processos de aprendizado. 0 que se entende aqui por processos de aprendizado vai bem além dos recursos pedagógicos do ensino [...] de história (quase sempre conotado com o termo "didática"). "Aprender" significa, antes, uma forma elementar da vida, um modo 
fundamental da cultura, no qual a ciência se conforma, que se realiza por ela e que a influencia de forma marcante. (RÜSEN, 2007, p. 87).

Percebe-se que a forma pela qual o autor toma a Didática, em suas reflexões, não se configura numa preocupação exclusivamente pautada nos recursos ou nas técnicas, não que o autor não reconheça tais funções, mas volta-se para a relação entre a didática e a aprendizagem, afirmando que o conceito de Didática é um tanto controvertido, por configurarse um domínio da Pedagogia, mas pondera que, se a Didática toma como preocupação a aprendizagem, tal entendimento é diretamente associado ao que ele entende por "aprender".

\begin{abstract}
Se "aprender" for entendido, fundamental e genericamente, como processo no qual as experiências e as competências são refletidas interpretativamente, esse conceito de aprendizado diz respeito ao que se discute aqui: a contribuição da ciência da história para o desenvolvimento daquelas competências da consciência histórica que são necessárias para resolver problemas práticos de orientação com o auxílio do saber histórico. (RÜSEN, 2007, p. 94).
\end{abstract}

Essa aprendizagem, que se expressa pela consciência histórica, é evidenciada por meio da elaboração de narrativas, que são construções coerentes elaboradas pelo sujeito levando em conta a forma pela qual este se relaciona com o passado.

A essa ideia, Barca (2007, p. 117) acrescenta que:

\begin{abstract}
[...] considera-se que "ter consciência histórica" avançada implica adquirir um certo sentido do que é a História como disciplina acadêmica, dominar determinadas competências historiográficas, construir uma narrativa consistente (não a narrativa) da condição humana (e não apenas do seu país) e refletir (e agir, intervir?) em consonância com o esquema mental que cada um vai dinamicamente formando.
\end{abstract}

Entende-se que Rüsen (2007) advoga favoravelmente a existência de uma Didática da História, tendo em vista que a História possui uma função didática, sendo seu objetivo investigar o aprendizado histórico.

0 aprendizado histórico é uma das dimensões e manifestações da consciência histórica. É o processo fundamental de socialização e individualização humana e forma o núcleo de todas estas operações. [...] Teoricamente, a didática da história tem de conceituar consciência histórica como uma estrutura e processo de aprendizado. [...] Metodologicamente, 
a didática da história pode usar métodos estabelecidos da psicologia e sociologia e reestruturá-los de acordo com a peculiaridade da consciência histórica. (RÜSEN, 2006, p. 15-16).

Tomando a valorização do que Rüsen chama de "aprendizado histórico", destacase o entendimento da História como o estudo da experiência humana, que permite evidenciar o lugar das experiências individuais e coletivas de homens e mulheres.

Schmidt e Garcia (2005, p. 299-300) afirmam que, ao assumir um dos princípios da Didática da História, que é de ordem teórica,

[..] torna necessário que professores e alunos busquem a renovação dos conteúdos, a construção de problematizações históricas, a apreensão de várias histórias lidas a partir de distintos sujeitos históricos, das histórias silenciadas, histórias que não tiveram acesso à História. Assim, busca-se recuperar a vivência pessoal e coletiva de alunos e professores e vêlos como participantes da realidade histórica, a qual deve ser analisada e retrabalhada, com o objetivo de convertê-la em conhecimento histórico, em autoconhecimento, uma vez que, desta maneira, os sujeitos podem inserirse a partir de um pertencimento, numa ordem de vivências múltiplas e contrapostas na unidade e diversidade do real.

Vale destacar que ao movimento sugerido pelas autoras com vistas à "renovação" pode-se agregar uma preocupação com a forma de ensinar, porém a diversidade dos sujeitos, as possibilidades de reflexão que tomam as vivências individuais e coletivas, o lugar onde se ensina e a forma como o conteúdo é tratado, seguramente, podem fazer toda a diferença.

Em suma, existem lógicas e estratégias na relação ensino/aprendizagem. Uma delas defende que a aprendizagem deve se processar em meio à ciência de referência, em situações concretas, ou seja, que façam sentido para quem aprende. "As vivências prévias dos sujeitos e a natureza específica do conhecimento, o tipo de tarefas a desempenhar, as aptidões individuais são aspectos fundamentais para a progressão do conhecimento." (BARCA, 2001, p. 20).

Assim, quando Rüsen $(2007,2010,2012)$ coloca a aprendizagem histórica e a relação com a consciência histórica como problema central da Didática da História, "[...] poderemos considerar que essa disciplina tem uma especificidade que pode ser levada em conta e vista como um substrato científico do domínio da Educação Histórica [...]" (SCHMDT; BARCA, 2014, p. 21).

Do ponto de vista epistemológico, a perspectiva rüseniana aponta para a área da Educação Histórica e para o fato de que 
[...] as pesquisas sobre aprendizagem histórica precisam ser fundamentadas na teoria da História e, por isso, uma das principais questões que se colocam em relação a essa temática é como deve ser levado em conta o papel da teoria da História nos processos investigativos relacionados à Educação Histórica [...] (SCHMDT; BARCA, 2014, p. 21).

\section{PESQUISAS EM EDUCAÇÃO HISTÓRICA}

As reflexões que envolvem a Didática da História e as relações entre ensino e aprendizagem, ancoradas nos pressupostos da Educação Histórica, desencadearam a realização de um conjunto de pesquisas que intencionam refletir sobre o que é ensinar e aprender História. Para esse conjunto de reflexões serão mencionadas algumas dessas pesquisas que foram desenvolvidas junto a programas de Pós-graduação Stricto Sensu em Educação e História da UFPR e da Unicentro. Cada pesquisa mencionada a seguir intenciona, à sua forma, empreender um debate com a escola e/ou com elementos da cultura escolar. Os resultados dessas pesquisas indicam a escolha pelo caminho da Educação Histórica por meio de um diálogo próximo com a escola e os sujeitos do universo escolar, nessa dinâmica, salvaguardando preocupações fundamentais que são, entre outras, a formação do(a) professor(a), seja esta inicial ou continuada. Nesse caso em particular, trata de pesquisas que abrem a interface justamente para esse espaço, da formação, e os desdobramentos naturais desse campo.

As pesquisas que vêm sendo desenvolvidas assumem um diálogo com as metodologias de investigação qualitativas, na área educacional, na direção do que Einser (1998, p. 28) defende como "indagação qualitativa":

\footnotetext{
[...] indagación cualitativa en educación trata de algo, es como intentar comprender lo que los profesores y los niños hacen en los grupos en los que trabajan. Para alcanzar este propósito l... es necesario "prestar atención" a las escuelas y las aulas por las que nos preocupamos, observarlas y utilizar lo que vemos como fuente de interpretación y valoración. ${ }^{5}$
}

As pesquisas também consideram a escola um espaço privilegiado de reflexão e investigação, assumindo na direção do que Ezpeletta e Rockwell (1986) apontam, a perspectiva 
da "construção social da escola", isto é, mesmo a escola sendo um lugar imerso num conjunto de situações, ela é reveladora de um movimento que a identifica, que a revela,

\begin{abstract}
[...] é impossivel encontrar duas escolas iguais. [...] Na verdade, cada escola é produto de uma permanente construção social. Em cada escola, interagem diversos processos sociais. [...] A realidade cotidiana das escolas sugere que não se trata de uma relação fixa, "natural", dada onde invariavelmente os professores e as crianças que nela convivem interiorizam valores e conteúdos [...] (EZPELEETTA; ROCKWELL, 1986, p. 58).
\end{abstract}

Considerando esses dois pressupostos - a indagação qualitativa e a construção social da escola - é que algumas investigações vêm sendo realizadas na perspectiva da Educação Histórica. ${ }^{6}$ Para este artigo, destacamos algumas pesquisas concluídas entre 2017 e 2019 que, cada uma a sua maneira, voltaram seu olhar para a escola como espaço dinâmico, como fonte de investigação, na esteira de Einser (1998).

Quadro 1 - Educação Histórica e a História Local

\begin{tabular}{|l|l|c|}
\hline \multicolumn{1}{|c|}{ Autores } & \multicolumn{1}{|c|}{ Título } & Ano \\
\hline Jesus, E. L. de & $\begin{array}{l}\text { História local: ideias de sentido histórico nas narrativas de alunos do ensino } \\
\text { médio de uma escola da rede pública estadual do município de Fernandes } \\
\text { Pinheiro, PR }\end{array}$ & 2018 \\
\hline Czarnieski, H. K. & $\begin{array}{l}\text { Concepção de história local presente no ensino de história do município de } \\
\text { Guarapuava-PR: uma análise na perspectiva da educação histórica }\end{array}$ & 2019 \\
\hline Sukow, N. M. & $\begin{array}{l}\text { História local como um pressuposto epistemológico da Didática da História: um } \\
\text { estudo a partir da perspectiva da Educação Histórica }\end{array}$ & 2019 \\
\hline
\end{tabular}

Fonte: os autores.

As análises da aprendizagem histórica a partir da história local na perspectiva da Educação Histórica privilegiam a investigação das ideias, dos significados e dos sentidos empregados pelos estudantes e professores quando estudam a história local, em detrimento de exames de políticas públicas, propostas curriculares e materiais didáticos de história local.

A pesquisa de Jesus (2018) investigou o modo como os jovens matriculados no ensino médio da Escola Estadual do Campo de Bituva das Campinas, localizada no

6 Cabe ressaltar que pesquisas identificadas com o campo da Educação Histórica são desenvolvidas em várias universidades brasileiras, como: Universidade Estadual de Londrina (UEL), Universidade Federal de Mato Grosso (UFMT), Universidade Estadual do Sudoeste da Bahia (UESB), Universidade Federal de Mato Grosso do Sul (UFMS), Universidade Estadual do Paraná (Unespar) e Universidade Estadual de Maringá (UEM). 
Município de Fernandes Pinheiro, PR, atribuem sentido histórico em suas narrativas históricas sobre a localidade onde vivem. 0 conceito de sentido histórico é central na concepção de aprendizagem histórica assumido pela Educação Histórica, a partir do diálogo com a Didática da História descrito anteriormente. 0 trabalho com a escrita de narrativas históricas em sala de aula possibilita a construção de representações de continuidade temporal de indivíduos e sociedades. Por intermédio da narrativa, pode-se estabelecer sentido entre as dimensões temporais do passado, do presente e do futuro e, assim, construir e reconstruir histórias, as quais são incorporadas no quadro de orientação da vida prática humana. A pesquisa contou com a participação de estudantes dos três anos do ensino médio, totalizando 39 jovens na faixa etária de 14 a 18 anos. Um dos aspectos que podemos destacar na investigação desse trabalho é o predomínio da memória familiar como fonte para acessar o passado nas narrativas sobre a Cidade de Fernandes Pinheiro, PR.

Czarnieski (2019) examinou, em seu trabalho, as concepções de história local presentes na rede municipal de ensino de Guarapuava, PR. Para isso, debruçou-se sobre a proposta curricular de História do ensino fundamental I e materiais didáticos de história e levantou, principalmente, as ideias dos professores dos anos iniciais do ensino fundamental a respeito do ensino e aprendizagem da história local. Nessa pesquisa, considerou-se a proposta curricular e os materiais didáticos como fonte de pesquisa, justamente por entender que esses documentos são fontes visíveis da vida na escola, assim como consideraram-se as ideias históricas dos professores como fonte para compreender suas práticas na escola. A rede municipal de educação do Município de Guarapuava, PR, tem 43 escolas; no entanto, a pesquisadora trabalhou com seis escolas e 26 professoras que atuam nos anos iniciais do ensino fundamental.

Com relação às concepções de história local das professoras investigadas, é interessante notar a presença de pontos de vista próximos de memorialistas locais de forte viés tradicional, centrado na história política e administrativa do Município. Contudo, alguns docentes estão preocupados com o desenvolvimento do pensamento histórico plural a partir do trabalho com mudanças e permanências. Outro aspecto a se destacar no encaminhamento das atividades de sala de aula é o resquício da perspectiva dos estudos sociais (disciplina criada no pós-golpe militar de 1964) aplicada ao ensino de história local, como exercícios de círculos concêntricos e abordagem moral da história.

Com o objetivo de entender como a História Local está presente no ensino de História no Brasil e quais concepções de aprendizagem norteiam essa presença, Sukow (2019) sistematizou uma análise almejando perceber como a História Local foi sendo compreendida ao longo da trajetória da História enquanto disciplina escolar no Brasil. Para tanto, utilizou-se de documentos e produção acadêmica como fonte e trouxe elementos para pensar a História Local enquanto um pressuposto epistemológico da Didática da História pela sua capacidade de relacionar vida prática e ciência. Os resultados da investigação apontaram que a História 
Local em específico e a História como um todo não devem estar no currículo unicamente pelo seu papel na formação de cidadãos. Essa é uma ideia generalista, pois, ao fim e ao cabo, a presença de qualquer disciplina pode ser justificada por essa perspectiva. Assim, a História Local, como a História, deve estar no currículo pelas características epistemológicas que a diferencia das outras ciências, isto é, sua presença no ensino de História escolar deve ser justificada pelo seu papel na formação da consciência histórica, já que está nas carências de orientação dos estudantes.

Quadro 2 - Educação Histórica, conceito substantivo e estudantes como sujeitos

\begin{tabular}{|l|l|c|}
\hline \multicolumn{1}{|c|}{ Autores } & \multicolumn{1}{c|}{ Título } & Ano \\
\hline Becker, G. & $\begin{array}{l}\text { Consciência histórica e atribuição de sentido: perspectivas de jovens estudan- } \\
\text { tes do ensino médio em relação à história da cidade de Curitiba }\end{array}$ & 2017 \\
\hline $\begin{array}{l}\text { Freitas, A. D. } \\
\text { G. de }\end{array}$ & $\begin{array}{l}\text { Consciência histórica e ciberespaço: análise de fontes históricas e as mudan- } \\
\text { ças na atribuição de sentido histórico em estudantes do ensino médio }\end{array}$ & 2017 \\
\hline
\end{tabular}

Fonte: os autores.

A investigação de Becker (2017), Consciência histórica e atribuição de sentido: perspectivas de jovens estudantes do ensino médio em relação à história da cidade de Curitiba, teve como objeto de estudo a consciência histórica de jovens estudantes do Ensino Médio relativa às operações mentais do pensamento histórico, fundamentadas na constituição de sentido dedicado à experiência do tempo. Entre os objetivos da pesquisa destaca-se a reflexão sobre a consciência histórica e a atribuição de sentido de jovens estudantes do ensino médio com relação à história da Cidade de Curitiba, PR. Os resultados possibilitaram algumas reflexões: sobre a escolha das fontes, percebeu-se que algumas foram escolhidas para demonstrar que Curitiba é uma Cidade turística, outras estavam relacionadas às carências de orientação temporal, à identificação e ao envolvimento por uma experiência de vida; e, por fim, algumas ligadas a elementos da cultura histórica desses jovens estudantes.

Já a pesquisa de Freitas (2017) buscou compartilhar reflexões sobre a comunicação e o ensino de história, suas interconexões e a influência das novas mídias na construção da consciência histórica de estudantes. Por meio da pesquisa, foi possível examinar que os estudantes interpretam as fontes criadas nos novos meios a partir de uma nova orientação temporal. lgualmente, o pesquisador percebeu que elementos da cultura histórica estão presentes nas fontes e nas arguições dos estudantes que participaram da pesquisa. 
Quadro 3 - Educação Histórica e a história difíil

\begin{tabular}{|l|l|c|}
\hline \multicolumn{1}{|c|}{ Autores } & \multicolumn{1}{|c|}{ Título } & Ano \\
\hline Neves, J. N. das & $\begin{array}{l}\text { Educação Histórica e educação escolar indígena: como as crianças e jovens } \\
\text { estudantes da etnia Mbyá Guarani se relacionam com a "história difícil" }\end{array}$ & 2018 \\
\hline Caldas, C. C. & $\begin{array}{l}\text { Religiões de matriz africana como um tema controverso: diálogos possiveis } \\
\text { entre cultura histórica e a cultura escolar }\end{array}$ & 2019 \\
\hline
\end{tabular}

Fonte: os autores.

A pesquisa Educação Histórica e educação escolar indígena: como as crianças e jovens estudantes da etnia Mbyá Guarani se relacionam com a "história difícil", de Neves (2018), teve como objetivo principal refletir sobre a consciência histórica desses estudantes com relação à "história dificil", utilizando como critério de tema o difícil/controverso. 0 estudo foi realizado junto a estudantes de uma escola indígena e revelou, a partir das ideias históricas e dos argumentos apresentados pelos estudantes, que a "história difícil" se manifesta na consciência histórica destes a partir de alguns aspectos, sendo eles: o impacto ecológico; a ruptura temporal e a captura; e a escravidão e o genocídio das populações indígenas. Essas questões foram consideradas as mais difíceis de narrar, pois quando narram o fazem de forma amargurada, tensa, traumática.

Caldas (2019) desenvolveu a pesquisa que considerou as religiões de matriz africana como um tema controverso e ancorou-se no referencial teórico da Educação Histórica. Ao tentar perceber essas religiões como um tema controverso na História do Brasil, intencionou demonstrar que, com base no Novo Humanismo, tal como é proposto por Jorn Rüsen, é possível contribuir para uma comunicação intercultural que possibilite a aceitação e o respeito ao outro, às diferenças, ao diferente. A pesquisa ressaltou que a ausência de certos temas dificulta a aprendizagem histórica de forma significativa e, consequentemente, a formação de uma consciência histórica mais complexa. 0 fato de ter de lidar com os fardos da história, com esses temas difíceis e controversos, é também um problema de funcionamento mental por meio de atividades intelectuais.

Quadro 4 - Educação Histórica, epistemologia da história e linguagens culturais

\begin{tabular}{|l|l|c|}
\hline \multicolumn{1}{|c|}{ Autores } & \multicolumn{1}{|c|}{ Título } & Ano \\
\hline Ferreira, S. A. da & $\begin{array}{l}\text { Formação inicial de licenciados em história e a didática da história: análise dos } \\
\text { projetos pedagógicos curriculares das Universidades Estaduais do Paraná }\end{array}$ & 2018 \\
\hline Waiga, J. M. & Educação Histórica e Ciências da Educação: diálogos epistemológicos & 2018 \\
\hline Oliveira, G. G. de & $\begin{array}{l}\text { Histórias em quadrinhos na construção de uma literacia histórica nos livros } \\
\text { didáticos presentes na cultura escolar }\end{array}$ & 2019 \\
\hline
\end{tabular}

Fonte: os autores. 
Ferreira (2018), assumindo a pesquisa sobre formação inicial de licenciados em história e a didática da história, analisou projetos pedagógicos curriculares dos cursos de História (PPCHs) das sete universidades estaduais do Paraná.

Para compreender os pressupostos da formação inicial de professores de História nas instituições estaduais de ensino superior, buscou-se estabelecer o seguinte percurso de pesquisa: a) reflexão acerca da formação inicial de docentes no Brasil, em especial na licenciatura em História; b) delimitação do campo da Didática da História e suas contribuições para a formação inicial; e c) análise das propostas nas dimensões contextuais e conceituais à luz dos princípios da Didática da História.

Os resultados da investigação indicam a ausência dos princípios epistemológicos da História na perspectiva formadora para o exercício da docência e que embora as propostas curriculares devessem atender às especificidades de cada contexto educacional, nada mais são que documentos muito parecidos e que, muitas vezes, correspondem apenas a uma carência burocrática.

No campo da Educação Histórica, Oliveira (2019), explorou o universo das histórias em quadrinhos e seu potencial para o desenvolvimento do conceito de literacia histórica na escola. Nessa direção, analisou 33 livros didáticos de história do ensino fundamental, adotados por oito escolas estaduais do Município de Irati, PR. 0 conceito de literacia histórica, central na pesquisa, foi trabalhado na perspectiva de Lee (2006). De acordo com o teórico, uma aprendizagem histórica é significativa para o estudante quando constrói conhecimentos que permitem leituras históricas da realidade. A partir desse pressuposto, observaram-se três categorias de uso das histórias em quadrinho nos livros didáticos analisados, a saber: a utilização como fonte histórica, como complemento da narrativa histórica do livro didático e como ilustração do texto. Concluiu-se que o uso como fonte histórica e complementação da narrativa histórica apresentam potencial de desenvolvimento da literacia histórica.

Já Waiga (2018), com a pesquisa Educação Histórica e Ciências da Educação: diálogos epistemológicos, teve como objetivo a identificação de contribuições e perspectivas provenientes dos diálogos da Educação Histórica com as Ciências da Educação. De acordo com o estudo, a continuidade desses diálogos epistemológicos da Educação Histórica com as Ciências da Educação pode contribuir para a construção de uma Didática da Educação Histórica, fundamentada na epistemologia da História e assessorada pelas Ciências da Educação. 0 investigador apontou que os diálogos realizados com as Ciências da Educação resultaram em contribuições para pesquisas em Educação Histórica, de ordem teórica, metodológica e categorial. 


\section{CONSIDERAÇÕES FINAIS}

Entendemos que as pesquisas mencionadas nesta reflexão representam uma parte de outras pesquisas que discutem e se preocupam com o ensino de História. Tratase de possibilidades de investigação que assumem o compromisso com a relação ensino/ aprendizagem para além dos formatos exatos ou receituários a serem cumpridos, mas principalmente assumem a ideia de que o professor também é pesquisador, justamente porque busca refletir, seja no espaço escolar seja por intermédio dos programas de pós-graduação.

Percebe-se o desafio de pensar sobre a formação do professor em meio ao processo de escolarização, no qual é possível encontrar todos os elementos que marcam cotidianamente a escola. Tais elementos, parte da cultura escolar, estão presentes nas pesquisas, bem como nas reflexões que pairam sobre discussões que envolvem as pesquisas identificadas com o campo da Educação Histórica.

A opção pelos fundamentos da Educação Histórica se assenta na epistemologia da História, na qual se assume a História como ciência de referência, apresentando-se como uma possibilidade para as configurações de pesquisa que se voltam ao ensino de História. Adotar o referencial da teoria da consciência histórica para as pesquisas que consideram a escola como uma construção social pressupõe assumir em conjunto a metodologia da pesquisa qualitativa, justamente por entender a escola e os sujeitos do universo escolar como parte de uma construção social.

No contexto das investigações desenvolvidas por grupos de pesquisa que encontram na Educação Histórica pressupostos para o desenvolvimento de seus trabalhos, é possível identificar uma variedade de temas de investigação, como aqueles que consideram as ideias dos alunos e professores, além daqueles que promovem o debate contido em manuais didáticos, em linguagens culturais, em currículos, entre outros. Essas pesquisas apontam uma estreita relação com o processo de escolarização e, nessa direção, voltam a sua preocupação ao ensino de História. Logo, as contribuições da Educação Histórica para a formação de professores passam justamente pelos desafios inerentes à própria natureza da escola e de todos que nela atuam.

Ademais, as investigações acerca da consciência histórica indicam a sua contribuição no debate sobre o conhecimento histórico e o seu significado para a construção de uma consciência histórica aliada aos fundamentos de um novo humanismo que se soma a uma educação libertária. 


\section{REFERÊNCIAS}

ANGEVIK, M.; BORRIES, B. Youth and history: a comparative European survey on historical consciousness and political attitudes among adolescents. Hamburg: Körber Foundation, 1997.

BARCA, I. Educação histórica: uma nova área de investigação. In: ARIAS NETO, J. M. (org.). Dez anos de pesquisas em ensino de História. Londrina: AtrioArt, 2005. p. 15-25.

BARCA, I. Educação histórica: uma nova área de investigação. Revista da Faculdade de Letras, III Série, v. 2, p. 13-21, 2001.

BARCA, I. Marcos de consciência histórica de jovens portugueses. Currículo sem fronteiras, v. 7, n. 1, p. ११५-१२६, jan./jun. 2007.

BECKER, G. Consciência histórica e atribuição de sentidos: perspectivas de jovens estudantes do Ensino Médio em relação à história da cidade de Curitiba. 2017. 109 f. Dissertação (Mestrado em Educação) - Universidade Federal do Paraná, Curitiba, 2017.

CALDAS, C. C. Religiões de matriz africana como um tema controverso: diálogos possíveis entre cultura histórica e a cultura escolar. 2019. 135 f. Dissertação (Mestrado em Educação) - Universidade Federal do Paraná, Curitiba, 2019.

CASTEX, L. C. 0 conceito substantivo ditadura militar brasileira (1964-1984) na perspectiva de jovens brasileiros: um estudo de caso em escolas de Curitiba - PR. 2008. 184 f. Dissertações (Mestrado em Educação) - Universidade Federal do Paraná, Curitiba, 2008.

CZARNIESKI, H. K. Concepção de história local presente no ensino de história do município de Guarapuava - PR: uma análise na perspectiva da educação histórica. 2019. 117 f. Dissertação (Mestrado em História) - Universidade Estadual do Centro-Oeste, Irati, 2019.

EISNER, E. W. El ojo ilustrado: indagación cualitativa y mejora de la práctica educativa. Barcelona: Paidós, 1998.

EZPELETTA, J.; ROCKWELL, E. Pesquisa participante. São Paulo: Cortez; Autores Associados, 1986.

FERREIRA, S. A. Formação inicial de licenciados em história e a didática da história: análise dos projetos pedagógicos curriculares das Universidades Estaduais do Paraná. 2018. 141 f. Dissertação (Mestrado em Educação) - Universidade Estadual do Centro-Oeste, Irati, 2018.

FREITAS, A. D. G. Consciência histórica no ciberespaço: análise de fontes históricas e as mudanças na construção de sentido histórico em estudantes do ensino médio. 2017. 114 f. Dissertação (Mestrado em Educação) - Universidade Federal do Paraná, Curitiba, 2017. 
JESUS, E. L. História local: ideias de sentido histórico nas narrativas de alunos do ensino médio de uma escola da rede pública estadual do município de Fernandes Pinheiro - PR. 2018. 112 f. Dissertação (Mestrado em História) - Universidade Estadual do Centro-Oeste, Irati, 2018.

JUNG, H.; STAHER, G. Didáctica de la historia y enseñanza de la historia em la Alemania unificada. Revista Conciencia Social, n. 2, p. 133-148, 1998.

LEE, P. Progressão da compreensão dos alunos em história. In: BARCA, I. Perspectivas em Educação Histórica. Braga: CEEP; Universidade do Minho, 2001. p. 13-27.

LEE, P. Walking backing into tomorrow: historical consciousness and understanding history. In: ANNUAL MEETING OF AMERICAN EDUCATIONAL RESEARCH ASSOCIATION, 2002, New Orleans. Proceedings [...] New Orleans: American Educational Research Association, 2002. p. 1-45.

NEVES, J. N. Educação histórica e educação escolar indígena: como as crianças e jovens estudantes da etnia Mbyá Guarani se relacionam com a "história difícil". 2018. 115 f. Dissertação (Mestrado em Educação) - Universidade Federal do Paraná, Curitiba, 2018.

OLIVEIRA, G. G. Histórias em quadrinhos na construção de uma literacia histórica nos livros didáticos presentes na cultura escolar. 2019. 90 f. Dissertação (Mestrado em Educação) - Universidade Estadual do Centro-Oeste, Irati, 2019.

RÜSEN, J. Aprendizado histórico. In: SCHMIDT, M. A.; BARCA, l.; MARTINS, E. R. (Orgs.). Jörn Rüsen e o ensino de história. Curitiba: Editora UFPR, 2010. p. 41-49.

RÜSEN, J. Aprendizagem histórica: fundamentos e paradigmas. Curitiba: W. A. Editores, 2012.

RÜSEN, J. Didática da história: passado, presente e perspectivas a partir do caso alemão. Práxis Educativa, v. 1, n. 2, p. 7-16, jul./dez. 2006.

RÜSEN, J. História viva: teoria da história: formas e funções do conhecimento histórico. Brasilia, DF: Editora da Universidade de Brasilia, 2007.

RÜSEN, J. Razão histórica: teoria da história: os fundamentos da ciência histórica. Brasilia, DF: Editora da Universidade de Brasília, 2001.

SCHMIDT, M. A. M. S.; BARCA, I. Uma epistemologia da pesquisa em educação histórica: limites e possibilidades. In: SCHMIDT, M. A. M. S. et al. (org.). Passados possíveis: a educação histórica em debate. ljuí: Ed. Unijuí, 2014. p. 21-39.

SCHMIDT, M. A. M. S. Cognição histórica situada: que aprendizagem histórica é esta? In: SCHMIDT, M. A. M. S.; BARCA, I. (org.). Aprender história: perspectivas da educação histórica. ljuí: Ed. Unijuí, 2009b. p. 21-51. 
SCHMIDT, M. A. M. S. Concepções de aprendizagem histórica presentes em propostas curriculares brasileiras. História Revista, v. 14, n. 1, p. 203-213, jan./jun. 2009a.

SCHMIDT, M. A. M. S.; GARCIA, T. M. F. B. A formação da consciência histórica de alunos e professores e o cotidiano em aulas de História. Caderno Cedes, v. 25, n. 67, p. 297-308, set./dez. 2005.

SUKOW, N. M. História local como um pressuposto epistemológico da didática da história: um estudo a partir da perspectiva da educação histórica. 2019. 210 f. Dissertação (Mestrado em Educação) Universidade Federal do Paraná, Curitiba, 2019.

WAIGA, J. M. Educação histórica e ciências da educação: diálogos epistemológicos. 2018. १२०f. Dissertação (Mestrado em Educação) - Universidade Federal do Paraná, Curitiba, 2018.

Endereço para correspondência: Rua Professora Maria Roza Zanon de Almeida, s/n, Irati, Paraná, Brasil; geysog@gmail.com

Roteiro, Joaçaba, U. 45, p. 1-22, jan./dez. 2020 | e22375 |E-ISSN 2177-6059 
